\title{
Use of an interactive, faith-based kiosk by congregants of four predominantly, African-American churches in a metropolitan area
}

\author{
Scott A. Dulchavsky ${ }^{1}{ }^{*}$, Wilma J. Ruffin ${ }^{1}$, Dayna A. Johnson ${ }^{2}$, Chad Cogan ${ }^{2}$ and Christine L. M. Joseph ${ }^{2}$ \\ 1 Department of Surgery, Henry Ford Hospital, Detroit, MI, USA \\ ${ }^{2}$ Department of Public Health Sciences, Henry Ford Hospital, Detroit, MI, USA
}

Edited by:

Badu Sarkodie, Ghana Health Service, Ghana

\section{Reviewed by:}

Milka Dančević-Gojković, Public Health Institute of Federation of Bosnia and Herzegovina, Bosnia and Herzegovina

Samuel D Towne, University of South Carolina, USA

\section{*Correspondence:}

Scott A. Dulchavsky, Henry Ford Health System, Department of

Surgery, 2799 W Grand B/vd, Detroit, MI 48202, USA

e-mail: sdulcha1@hfhs.org
Chronic diseases are prevalent in ethnic communities. Churches represent a potent resource for targeted health promotion. A faith-based kiosk was developed as an informational tool and placed in four predominantly (>80\%) African-American churches. Congregants were surveyed to describe kiosk-use, kiosk-user characteristics, health status, and self-reported behavior changes attributed to the kiosk. We analyzed 1,573 questionnaires. Mean age of respondents was 46.4 years and $>70 \%$ were women. "Older" congregations (mean age $\geq 46.1$ years) had more reports of diabetes $(p=0.002)$ and heart diseases $(p=0.01)$ than younger churches (mean age $\leq 44.1)$, whereas asthma was more prevalent in the latter $(p<0.001)$. Prevalence of obesity $(40 \%)$ was similar across churches ( $p=0.570)$. Kiosk-use was reported by $420(26.7 \%)$ respondents. Compared to non-users, kiosk-users were $>40$ years $(p<0.001)$, and reported $>$ two health conditions, adjusted Odds Ratio (95\% Confidence Interval) $=1.43$ (1.0-2.0), $p=0.05$. Male kiosk-users preferred to select disease-specific content, $\mathrm{aOR}=1.87(1.10-3.17), p=0.02$, while females tended to select information about supportive community resources, aOR $=0.49(0.23-1.04), p=0.062$. Knowledge of kiosk-user characteristics and the "health status" of a congregation, provide an opportunity for targeted, church-based health promotion.

Keywords: kiosk, faith-based interventions, health information, health ministry, health disparities, chronic disease, minority health

\section{INTRODUCTION}

Discrimination and lack of health care resources in vulnerable communities contribute to unequal health outcomes. Access to health information and care is a great challenge for underserved populations in the United States and abroad, as low literacy may compound limited access to helpful health information $(1,2)$. These barriers to health information are difficult to overcome with traditional strategies.

Churches remain a consistent source of strength in ethnic and poorer communities, providing a home for the individual and the collective physical, emotional, and spiritual health of communities (3). Indeed, many believe that the church can play an important role in meeting the health needs of a congregation $(4,5)$.

The use of emerging information technology to provide health information on major urban health problems has the promise to empower individuals in underserved communities to improve their own health. Multimedia instructional methods such as video or pictorial-based stories have been shown to be substantially more effective than text-based solutions in a variety of communities, including underserved and ethnic populations (6-11). The effect of enhanced retention of information with visual learning is particularly pronounced in geriatric or low literacy groups, which comprise a large percentage of Medicare recipients (12).

The end of the twentieth century witnessed the growth of using kiosks to provide non-text-based personal communication on health issues. Gielen, et al. (13) demonstrated that parents in an urban pediatric hospital emergency department serving a predominantly low-income population increased their knowledge and attitudes about public health-related information after using kiosks based in this location (13). In one survey of kiosk-users, the majority responded that they planned to apply what they read and almost 50\% planned to speak with their physician about what they read on the kiosk (14). A significant aspect of communitybased kiosks is that they can provide tailored information to users. Research indicates that tailored information is more likely than non-tailored information to be viewed as personally relevant, and is more likely to be read and acted upon (15).

Henry Ford Health System (HFHS) partnered with the existing community infrastructures to improve health care literacy through a church-based health information kiosk system. This faith-based medical kiosk was designed with an intuitive, touch screen interface, and targeted populations that may have low health literacy skills. Each free-standing kiosk is customized to the congregation and incorporates messaging from church leaders. Users enter simple demographic information to direct each interaction. The touch screen kiosks are simple to use, requiring no computer knowledge and are built at an appropriate literacy level for the anticipated users.

We placed faith-based kiosks in four large, urban churches, under the guidance of the church health ministry. We then 
administered a questionnaire to church congregants 1-2 years after kiosk installation. The objective of the questionnaire was to (1) estimate kiosk-use among congregants, (2) describe kiosk-user characteristics, and health status, and (3) describe self-reported behavior changes attributed to use of the kiosk.

\section{MATERIALS AND METHODS SOFTWARE DEVELOPMENT}

This interactive, multimedia software program was designed on an industry standard platform using a Director ${ }^{\mathrm{TM}}$ development program. The kiosk provides examples of positive family interaction to provide good role models of healthy behavior. Each medical condition presented is contextualized in a family setting. A multigenerational family unit interacts candidly in a short video while discussing each condition (Figure 1).

The program begins with an introductory message by the pastor of the church explaining the purpose of the Health Kiosk, encouraging the user to explore sections of interest. Following the introductory video, questions are asked of the user to tailor the experience by age, gender, and health status. Additional questions are posed regarding smoking, exercise, and whether the user has a personal physician which set the user population baseline. The major modules included are cholesterol screening, hypertension, osteoporosis, memory loss, depression, sexually transmitted diseases, heart disease, stroke, cancer, HIV/AIDS, and healthy living. These modules provide detailed information on common symptoms, specific risk factors, preventative measures, and appropriate screening guidelines for early detection. Following the video, there is a more didactic presentation of evidence based information about the topics combined with rich media support, culturally appropriate, and diverse material. After the module, there is a second tier of interactions available - all calls to action in two major categories: Healthy Lifestyle Choices and Community support.

The software was fully developed in collaboration with Butler Graphics, Inc. The program was pilot-tested with groups from the faith-based community to assess user friendliness and design, to determine the key health issues of most concern to community members, and to determine how it might benefit the congregation. To our knowledge, there is no other comparable software on the market. HFHS has begun the application process for a patent.

\section{SURVEY OF CHURCH MEMBERSHIP}

To assess the impact of the kiosk (usage rates, self-report of behavior change, and overall acceptability), a questionnaire was developed through a collaborative effort between HFHS and Church Health Ministry Leaders and Pastors. Churches also discussed how they might use the health information in the kiosks. The questionnaire had a total of 27 items. Requested was respondent demographic information, respondent experiences with the kiosk, the health status of the respondent, and the health status of respondent family members. Names of respondents or any identifying information was not requested. The questionnaire was pilot-tested in a subset of congregants and leaders from each church participant to develop a standardized protocol for administration. The HFHS IRB approved the questionnaire and the questionnaire protocol.

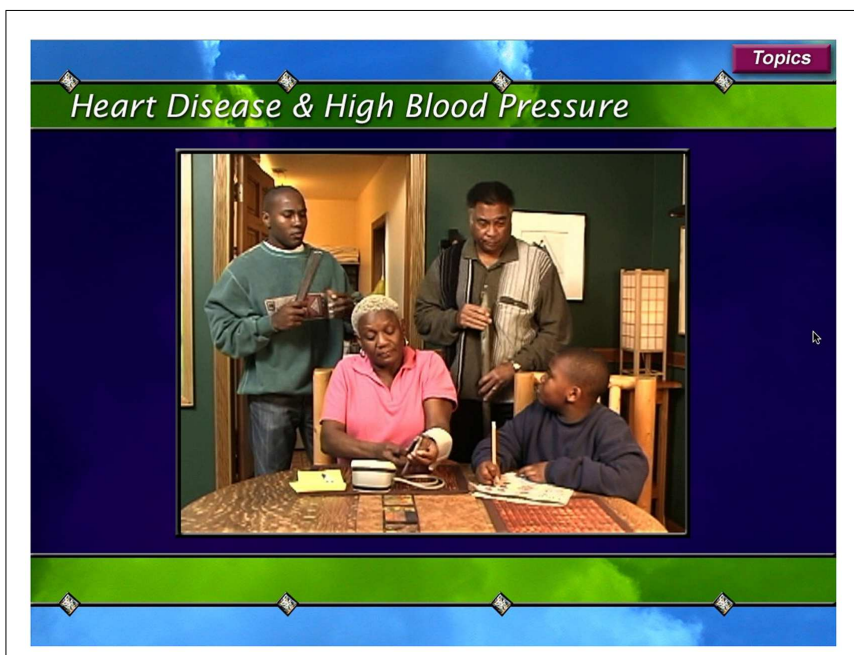

FIGURE 1 | Faith-based Kiosk: "Blood Pressure Module grandmother taking blood pressure with grandson, son and grandfather".

The questionnaire was administered to the four participating churches from March-May, 2009. Letters were sent to Pastors and Health Ministries informing them of the upcoming evaluation and requesting their support. In preparation, research staff organized an orientation/training session with church staff members to discuss the logistics of administering the survey. Churches were contacted 3 days prior to survey distribution to confirm participation. Questionnaires were distributed by research staff at each service on one Sunday and handed to every member of the church that was 18 years of age or older upon their entry into the sanctuary. During and following the service, the congregants were reminded to complete and submit their questionnaire to an HFHS staff member in a designated area. Each church received $\$ 5.00$ for every completed survey, with the maximum allowance of $\$ 5,000$. As congregants submitted their questionnaire, they were given a tote bag, key chain, first aid kit, or small key chain flashlight.

\section{STATISTICAL ANALYSIS}

Demographic information and self-reported prevalence of health conditions was summarized for each church. Age was reported using means and standard deviations. To examine differences across churches, a one-way analysis of variance was used to test for statistically significant differences in mean age for at least one comparison among the four churches. A chi-square test was used to determine if responses were statistically different across the four churches. Associations with a $p$-value $<0.05$ were considered statistically significant.

To assess the independent association of demographic variables and other survey items to use of the kiosk, a multiple logistic regression model with user/non-user as the dependent variable, was constructed and included all variables of interest (age, race, gender, number of health conditions reported, and family member with a health condition), adjusting for church membership. In these models, prevalence of health condition(s) was coded as none, 1,2 , or 3 or more. 
We also examined the relationship between gender and section viewed. Only sections with bivariate chi-square results yielding a $p$-value $<0.20$ were examined further using multiple logistic regression. For these sections, a multiple logistic regression was run in which section viewed (yes/no) as the dependent variable. Each model contained gender, age, and church membership.

Finally, we created a model to assess factors associated with self-report of behavior change. Variables in the model were age, race, gender, self-report of health condition(s) (coded as none, 1, 2 , or 3 or more), having a family member with a health condition (yes/no). The model was also adjusted for church membership.

As noted above, less stringent $p$-values $(<0.20)$ were used in the building of some models, however, for the final multiple logistic regression models, $p<0.05$ was considered statistically significant. All analyses were conducted using SAS software version 9.2.

\section{RESULTS}

CHARACTERISTICS OF RESPONDENTS AND ESTIMATED USE OF KIOSK

The four participating churches ranged in congregation membership from 1500 to 6000 , with usual church attendance on Sunday ranging from 500 to 2000 according to estimates provided by church staff. The estimated percentage of surveys returned was $421 / 500$ (84\%), 38\% ( $n=305 / 800) 40 \%(n=792 / 2000)$, and $46 \%$ ( $n=461 / 1000)$ for a combined total of 1979 for the four participating churches (Church A, B, C, D, respectively), of which 79.5\% $(n=1573)$ had data usable for this descriptive analysis. Of those, $420(26.7 \%)$ reported using the kiosk (range 19.1-35.4\%).

Respondent characteristics are presented in Table 1, along with demographics and self-report of respondent and respondent family members' health status. Respondents from all four churches were mostly African-American $(>80 \%)$ and the percentage of males ranged from 18.1 to $27.5 \%$. Across churches, the range in mean age was $41.6-54.8$ (overall $p<0.001$ ). The age difference between the church with the oldest surveyed members (Church A) and the youngest (Church B) was statistically significant $(p<0.001)$.

Percentage of respondents reporting certain health conditions is shown in Table 1. Church A, with the highest overall mean age of 54.8 years, also had the highest reports of diabetes, heart disease, hypertension, and arthritis. Church B, with the lowest overall mean age of 41.6 years, was only highest in self-report of asthma. Despite significant age differences in the congregants surveyed, the percentage of respondents reporting obesity across churches was similar. Church B, with the youngest mean age for those surveyed, had a self-reported percentage of obesity similar to that of churches with higher overall mean ages, 39.8 vs. $42.6 \%$ and $40.9 \%$ for Churches B, A, and D, respectively (Table 1). With the exception of obesity, Church D, with the second highest mean age, was lowest in reports of diabetes, heart disease, hypertension, asthma, and arthritis. Church D also had the lowest report of cancer, although differences across churches were not significant (Table 1).

\section{CHARACTERISTICS OF KIOSK-USERS}

Table 2 shows the results of a multiple logistic regression conducted to obtain independent associations of demographic characteristics and number of health conditions reported to use of the kiosk. All associations are adjusted for church.
Older age was associated with kiosk-use: adjusted odds ratios (OR) and confidence intervals (CI) for "40-59.9 years" and “ $\geq 60$ years" were, $\mathrm{OR}=1.63,95 \% \mathrm{CI}: 1.27-2.09)$ and $\mathrm{OR}=1.52$, 95\% CI:1.07-2.15; $(p<0.001$ and $p=0.019)$, respectively. Race and gender were not associated with use of the kiosk. Compared to respondents reporting no health conditions, respondents with two health conditions were more likely to use the kiosk $(p=0.05)$. A higher percentage of respondents who reported a family member with a health condition used the kiosk compared to those without such a report, $[\mathrm{OR}=1.29,95 \% \mathrm{CI}: 0.98,1.69]$, but this was of borderline significance $(p=0.069)$.

We examined the association of gender to sections viewed in the kiosk. Bivariate $p$-values $<0.20$ for chi-square analysis of section viewed by gender included Diabetes $(p=0.016)$, Power of Prayer $(p=0.097)$, Support and Resources $(p=0.026)$, and High Blood Pressure $(p=0.150)$. Results of multiple logistic regression, adjusting for age and church membership, are shown in Table 3. Men were more likely to view Diabetes $[\mathrm{aOR}=1.8795 \% \mathrm{CI}: 1.10$ 3.17] $(p=0.02)$ and a higher percentage (not significant) viewed High Blood Pressure (53.2\% of men vs. $44.1 \%$ of women). A higher percentage of women viewed Support and Resources content (13.9\% of men vs. $25.8 \%$ of women), which was very close to our predetermined level of statistical significance $[\mathrm{aOR}=0.49$, 95\% CI: 0.23-1.04] ( $p=0.062)$.

\section{SELF-REPORT OF BEHAVIOR CHANGE}

Report of behavior change ranged from $69 \%$ for increased physical activity to $5.5 \%$ for receipt of a flu shot. In addition to increases in physical activity, $68.8 \%$ reported changes in diet, and 65.5 reported better communication with a physician. A total of $14.5 \%$ reported no change in behavior after viewing the kiosk.

Table 4 shows the results of the multivariable analysis for association of selected variables to self-report of behavior change. Adjusted OR were elevated for African-American race, male gender, and report of a health condition. The latter relationship reached statistical significance only for persons reporting one health condition. Also significant was behavior change reported among kiosk-users caring for a family member with a health condition (Table 4).

\section{DISCUSSION}

We introduced a Faith-based kiosk to four churches with predominantly African-American congregations and collected descriptive data on users. The kiosk focused on a variety of health areas and incorporated religious principles that corroborated healthy living. The kiosk also was a source of information on community resources.

The main findings of our analysis apply to the use of the kiosk. Across the churches, approximately $25 \%$ of the survey respondents reported using the kiosk and more than half who used the kiosk for a specific health condition reported making positive changes in health-related behaviors. Congregant characteristics associated with kiosk-use included age (persons $40+$ were more likely to use the kiosk) and having a health condition (e.g., diabetes, hypertension, etc.). As might be expected, having a health condition, and/or caring for a family member with a health condition was associated with self-report of change; however, these factors are 


\begin{tabular}{|c|c|c|c|c|c|}
\hline & Church A & Church B & Church C & Church D & $\begin{array}{l}\text { Overall } \\
p \text {-value }\end{array}$ \\
\hline Total surveyed & 421 & 305 & 792 & 461 & - \\
\hline Estimated usual church attendance & $N=500$ & $N=800$ & $N=2000$ & $N=1000$ & \\
\hline Reported using kiosk & $61(19.1 \%)$ & $80(32.4 \%)$ & $144(23.0 \%)$ & $135(35.4 \%)$ & $<0.01$ \\
\hline Age, mean (SD) & $54.8(14.9)$ & $41.6(14.7)$ & $44.1(13.4)$ & $46.1(14.4)$ & $<0.001^{\mathrm{c}}$ \\
\hline African-American, $n(\%)$ & $373(88.6 \%)$ & $258(84.6 \%)$ & $661(83.5 \%)$ & $416(90.2 \%)$ & 0.003 \\
\hline Male, $n(\%)$ & $95(26.2 \%)$ & $68(26.1 \%)$ & $125(18.1 \%)$ & $118(27.5 \%)$ & $<0.001$ \\
\hline Family member with health condition, $n(\%)$ & $140(50.5 \%)$ & $120(55.6 \%)$ & $289(54.3 \%)$ & $153(46.9 \%)$ & 0.120 \\
\hline
\end{tabular}

\begin{tabular}{|c|c|c|c|c|c|c|c|}
\hline \multirow[b]{2}{*}{ Health Conditions, $n(\%)$} & \multicolumn{2}{|c|}{$\begin{array}{l}\text { US estimates age adjusted } \\
\text { percentages }\end{array}$} & & & & & \\
\hline & All adults $(\%)^{d}$ & $\begin{array}{l}\text { US African- } \\
\text { Americans (\%)e }\end{array}$ & & & & & \\
\hline Diabetes & 8.7 & 13.1 & $81(28.7 \%)$ & $46(23.6 \%)$ & $98(18.6 \%)$ & $58(17.4 \%)$ & 0.002 \\
\hline Heart disease & 11.5 & 11.2 & $38(15.3 \%)$ & 17 (9.9\%) & 42 (8.6\%) & $24(7.7 \%)$ & 0.013 \\
\hline High blood pressure & 24.0 & 32.2 & $216(65.7 \%)$ & $108(49.3 \%)$ & $269(45.9 \%)$ & $156(41.9 \%)$ & $<0.001$ \\
\hline Obesity & 27.2 & 37.6 & $110(42.6 \%)$ & $74(39.8 \%)$ & $196(37.7 \%)$ & $140(40.9 \%)$ & 0.570 \\
\hline HIV/AIDs or STDs & $<1$ & $<1$ & $20(8.9 \%)$ & $22(13.9 \%)$ & $61(13.1 \%)$ & $28(9.3 \%)$ & 0.165 \\
\hline Asthma & $13.0^{f}$ & 13.8 & $53(22.0 \%)$ & $45(25.4 \%)$ & $98(20.3 \%)$ & $36(11.5 \%)$ & $<0.001$ \\
\hline Arthritis & 22.1 & 23.1 & $138(48.9 \%)$ & $62(32.8 \%)$ & $151(29.0 \%)$ & $87(26.0 \%)$ & $<0.001$ \\
\hline Cancer & $7.9^{9}$ & 4.4 & 30 (12.4\%) & $15(9.3 \%)$ & $40(8.3 \%)$ & $20(6.5 \%)$ & 0.106 \\
\hline Osteoporosis ${ }^{h}$ & 18 & 7.0 & $15(16.9 \%)$ & $5(20.0 \%)$ & $13(13.3 \%)$ & $14(11.3 \%)$ & 0.623 \\
\hline
\end{tabular}

a Percentages calculated from non-missing responses.

${ }^{b} A l l p$-values based on Chi-squared test unless otherwise noted.

${ }^{c} p$-Value based on one-way ANOVA.

¿18 years of age and older.

eIncludes persons selecting Black or African-American only.

${ }^{\dagger}$ Ever diagnosed.

${ }^{g}$ Denominator is women aged 50 years and up.

likely what attracted congregants to the kiosk. Our results also suggest that men used the kiosk more to obtain information; whereas women used the kiosk to look for supportive resources. The literature suggests that African-American men are less likely to visit the physician and less likely to ask questions during a clinic visit. A kiosk may represent a more acceptable vehicle for delivering health information to specific subgroups, such as African-American men. According to our survey, men were as likely as women to use the kiosk, despite selecting different content, and results of this survey could be used to develop gender-specific promotion messages to encourage use.

As might be expected, having a health condition and/or caring for a family member with a health condition was associated with self-report of change. These factors are likely what attracted congregants to the kiosk.

Our results also illustrate how the "collective health" of congregations can vary. Interesting differences in congregant characteristics were noted across churches. Older congregations reported more health problems, with the important exception of obesity, for which the prevalence did not differ significantly between churches, regardless of age or gender distribution.
Church D, with the second highest mean age, actually had a lower proportion of respondents with diabetes, heart disease, high blood pressure, asthma, arthritis, and cancer. Possible reasons for this difference include (1) the mean age of Church D is only indicative of survey respondents and not the entire church congregation; (2) healthier respondents were more likely to complete the survey at Church D; (3) healthier persons are drawn to healthier congregations; or (4) these differences are related to variations in socioeconomic status between churches. Church D also had the largest percentage of congregants who reported using the kiosk. We posit that the above trend could also be due to church leadership or a church environment that is supportive of health improvements and a healthy lifestyle. Reasons for variations in collective health across congregations should be explored as this may inform church-based interventions.

To our knowledge, there are few faith-based kiosk programs aimed at promoting healthy behaviors in use in urban, AfricanAmerican churches. Health based kiosks are present in a variety of community settings but publications are few. Some findings from our study are consistent with earlier research regarding health 
Table 2 | Association of demographic characteristics, self-report of health conditions, and family member health status by use of faith-based kiosk (all churches) using multiple logistic regression.

\begin{tabular}{|c|c|c|c|c|c|c|c|c|}
\hline & \multicolumn{4}{|c|}{ Kiosk-Use } & \multirow[t]{2}{*}{ Total } & \multirow[t]{2}{*}{$\mathrm{aOR}^{\mathrm{c}}$} & \multirow[t]{2}{*}{$95 \% \mathrm{Cl}^{\mathrm{d}}$} & \multirow[t]{2}{*}{$p$-Value } \\
\hline & \multicolumn{2}{|c|}{ Yes } & \multicolumn{2}{|c|}{ No } & & & & \\
\hline \multicolumn{9}{|l|}{ Age } \\
\hline$<40$ & 158 & 37.6 & 551 & 47.8 & 709 & Reference & & \\
\hline \multicolumn{9}{|l|}{ Race } \\
\hline Non-African-American & 47 & 11.2 & 139 & 12.1 & 186 & 1.06 & $(0.74,1.52)$ & 0.738 \\
\hline African-American & 373 & 88.8 & 1014 & 87.9 & 1387 & & & \\
\hline \multicolumn{9}{|l|}{ Gender } \\
\hline Male & 79 & 20.5 & 233 & 22.7 & 312 & 1.20 & $(0.89,1.60)$ & 0.230 \\
\hline 1 Reported & 112 & 29.6 & 325 & 31.4 & 437 & 1.07 & $(0.77,1.50)$ & 0.688 \\
\hline 2 Reported & 97 & 25.7 & 224 & 21.7 & 321 & 1.43 & $(1.00,2.03)$ & 0.050 \\
\hline 3 Or more reported & 89 & 23.5 & 245 & 23.7 & 334 & 1.20 & $(0.84,1.72)$ & 0.309 \\
\hline \multicolumn{9}{|c|}{ Family member with health condition } \\
\hline No & 132 & 44.3 & 396 & 50.4 & 528 & Reference & & \\
\hline Yes & 166 & 55.7 & 390 & 49.6 & 556 & 1.29 & $(0.98,1.69)$ & 0.069 \\
\hline
\end{tabular}

${ }^{a}$ Number of persons in the specified category.

${ }^{b}$ Percentage of the total for that strata; percentage of the total or number of persons in strata/total number with information for this variable.

'Adjusted odds ratio; all models adjusted for church.

${ }^{d} 95 \%$ Confidence interval for adjusted odds ratio.

Table 3 | Association between gender and kiosk sections viewed using multiple logistic regression (model size $=385$ )

\begin{tabular}{lccccc}
\hline \multicolumn{1}{c}{ Male $\boldsymbol{n}(\%)$} & Female $\boldsymbol{n}(\%)$ & aOR $^{\mathbf{a}}$ & $\mathbf{9 5 \%} \mathbf{C l}$ & $\boldsymbol{p}$-Value \\
\hline $\begin{array}{l}\text { Section(s) viewed } \\
\text { Diabetes }\end{array}$ & & & & \\
No $40(50.6 \%)$ & $200(65.4 \%)$ & 1.87 & $(1.10,3.17)$ & 0.020 \\
Yes $39(49.4 \%)$ & $106(34.6 \%)$ & & & \\
Power of prayer & & & & \\
No $62(78.5 \%)$ & $211(69.0 \%)$ & 0.61 & $(0.32,1.18)$ & 0.141 \\
Yes $17(21.5 \%)$ & $95(31.1 \%)$ & & & \\
Support and resources & & & & \\
No $68(86.1 \%)$ & $227(74.2 \%)$ & 0.49 & $(0.23,1.04)$ & 0.062 \\
Yes $11(13.9 \%)$ & $79(25.8 \%)$ & & & \\
High blood pressure & & & & \\
No $37(46.8 \%)$ & $171(55.9 \%)$ & 1.39 & $(0.80,2.43)$ & 0.243 \\
Yes $42(53.2 \%)$ & $135(44.1 \%)$ & & & \\
\hline
\end{tabular}

${ }^{a}$ Adjusted odds ratio and $95 \%$ Confidence Interval; all models adjusted for church and age.

kiosks, such as users being older than non-users and women more likely to be users than men $(16,17)$. In considering earlier studies, our report is unique in at least two ways: (1) the majority of
Table 4 | Factors associated with self-report of any change(s) in health behavior among kiosk-users using multiple logistic regression.

\begin{tabular}{|c|c|c|c|}
\hline & $\mathrm{aOR}^{\mathrm{a}}$ & $95 \% \mathrm{Cl}^{\mathrm{b}}$ & $p$-Value \\
\hline \multicolumn{4}{|l|}{ Age } \\
\hline$<40$ & Reference & & \\
\hline $40-59.9$ & 0.94 & $(0.40-2.18)$ & 0.877 \\
\hline$\geq 60$ & 0.86 & $(0.25-2.95)$ & 0.805 \\
\hline African-American race & 1.80 & $(0.38-8.47)$ & 0.457 \\
\hline Male gender & 1.78 & $(0.63-5.05)$ & 0.279 \\
\hline \multicolumn{4}{|l|}{ Self-report of health conditions } \\
\hline None reported & Reference & & \\
\hline 1 Reported & 3.47 & $(1.11-10.87)$ & 0.033 \\
\hline 2 Reported & 1.89 & $(0.66-5.42)$ & 0.234 \\
\hline 3 Or more reported & 1.27 & $(0.45-3.59)$ & 0.652 \\
\hline Family member with a health condition & 3.56 & $(1.39-9.10)$ & 0.008 \\
\hline
\end{tabular}

the work in this area has been conducted outside of the United States, and did not include respondents from ethnic populations; and (2) a noticeably higher percentage of respondents reporting use of the Faith-based kiosk (26.7\%) compared to prior reports in the literature of $13-16 \%(16-18)$. 
There are several limitations to our report. Response rates were generally $13-15 \%$ as best could be estimated using church statistics on the number of members on the roster at each church, and ranged from 46 to $84 \%$ using estimates for the number of congregants attending services on any given Sunday. Our estimates for self-report of health conditions should not be viewed as a true prevalence since our sample was not selected randomly. Sicker respondents are less likely to attend church, and therefore, may be underrepresented in our sample. As it stands, our results apply only to those congregants present and choosing to respond to the survey. We do not have information on self-report of behavior change for non-kiosk-users because of skip patterns in the questionnaire. Finally, we do not have accurate, objective measures of SES for survey respondents or congregations.

Using a kiosk to deliver health information has many challenges. In addition to the cost and installation of the kiosk, the number of kiosks necessary to serve a large congregation of 1000-2000 persons must be considered. Funding and technical expertise is required to download and analyze data, and to cover on or offsite technical support. Notwithstanding these challenges, a faith-based kiosk is an excellent way to deliver health education, provide information on available church or community resources, and reinforce health messages in the context of spiritual beliefs. Simultaneously, kiosks could be programed to obtain information on the health status of users, allowing compilation of data for aggregate reports, i.e., a church "Report Card," which could rally churches to monitor and adopt better health behaviors as a congregation, providing an opportunity for targeted health promotion.

Churches might be viewed as self-contained communities, or portals into a given community, through which a sizeable number of individuals can be reached. In addition to the data that we have collected, collection of detailed characteristics of church leadership and "environment" (i.e., the prioritization of health programs among other existing programs) will also provide valuable information on how congregations as a whole can be motivated to change behavior. Results of this descriptive analysis can inform the feasibility, acceptability, and the potential for Faith-based kiosks to promote health in urban and underserved communities. Next steps include a more rigorous evaluation that includes a comparison group and more objective and clinical measurement of behavioral and health outcomes.

\section{ACKNOWLEDGMENTS}

This research is supported by grants from Health Alliance Plan, the William Davidson Foundation, and the National Space Biomedical Research Institute through NASA NCC 9-58.

\section{REFERENCES}

1. Kreps GL. Disseminating relevant health information to underserved audiences: implications of the digital divide pilot projects. J Med Libr Assoc (2005) 93(Suppl 4):S68-73.

2. Szczepura A. Access to health care for ethnic minority populations. Postgrad Med J (2005) 81(953):141-7. doi:10.1136/pgmj.2004.026237
3. Peterson J, Atwood JR, Yates B. Key elements for church-based health promotion programs: outcome-based literature review. Public Health Nurs (2002) 19:401-11.

4. Watson D, Bisesi L, Tanamly S, Sim T, Branch C, Williams E III. The role of small and medium-sized African-American churches in promoting healthy life styles. J Relig Health (2003) 42(3):191-200. doi:10.1023/A:1024835500987

5. Swinney J, Anson-Wonkka C, Maki E, Corneau J. Community assessment: a church community and the parish nurse. Public Health Nurs (2001) 18:40-4. doi:10.1046/j.1525-1446.2001.00040.x

6. Austin PE, Matlack R II, Dunn KA, Kesler C, Brown CK. Discharge instructions: do illustrations help our patients understand them? Ann Emerg Med (1995) 25:317-20. doi:10.1016/S0196-0644(95)70286-5

7. Houts PS, Doak CC, Doak LG, Loscalzo MJ. The role of pictures in improving health communication: a review of research on attention, comprehension, recall, and adherence. Patient Educ Couns (2006) 61:173-90. doi:10.1016/j.pec.2005. 05.004

8. Mohrmann CC, Coleman EA, Coon SK, Lord JE, Heard JK, Cantrell MJ, et al. An analysis of printed breast cancer information for African American women. J Cancer Educ (2000) 15(1):23-7.

9. Murray E, Davis H, Tai SS, Coulter A, Gray A, Haines A. Randomised controlled trial of an interactive multimedia decision aid on hormone replacement therapy in primary care. BMJ (2001) 323:490-3. doi:10.1136/bmj.323.7311.493

10. Pott E TJ, Christiansen G. The important role of audio-visual media in aids prevention. International Conference on AIDS, 1996. Abstract no. Mo. D. 1820

11. Vargas RB, Jones L, Terry C, Nicholas SB, Kopple J, Forge N, et al. Communitypartnered approaches to enhance chronic kidney disease awareness, prevention, and early intervention. Adv Chronic Kidney Dis (2008) 15:153-61. doi:10.1053/j.ackd.2008.01.012

12. Myers DR, Sykes C, Myers S. Effective learner-centered strategies for teaching adults: using visual media to engage the adult learner. Gerontol Geriatr Educ (2008) 29:234-8. doi:10.1080/02701960802359466

13. Gielen AC, McKenzie LB, McDonald EM, Shields WC, Wang MC, Cheng YJ, et al. Using a computer kiosk to promote child safety: results of a randomized, controlled trial in an urban pediatric emergency department. Pediatrics (2007) 120:330-9. doi:10.1542/peds.2006-2703

14. Thompson DA, Lozano P, Christakis DA. Parent use of touchscreen computer kiosks for child health promotion in community settings. Pediatrics (2007) 119:427-34. doi:10.1542/peds.2006-2669

15. Ahern DK. Challenges and opportunities of eHealth research. Am J Prev Med (2007) 32:S75-82. doi:10.1016/j.amepre.2007.01.016

16. Courtenay WH. Behavioral factors associated with disease, injury, and death among men: evidence and implications for prevention. J Mens Studies (2000) 9(1):81-142. doi:10.3149/jms.0901.81

17. Shavers VL, Shankar S, Alberg AJ. Perceived access to health care and its influence on the prevalence of behavioral risks among urban African Americans. J Natl Med Assoc (2002) 94:952.

18. Addis ME, Mahalik JR. Men, masculinity, and the contexts of help seeking. Am Psychol (2003) 58:5-14. doi:10.1037/0003-066X.58.1.5

Conflict of Interest Statement: The authors declare that the research was conducted in the absence of any commercial or financial relationships that could be construed as a potential conflict of interest.

Received: 19 December 2013; accepted: 18 July 2014; published online: 05 August 2014. Citation: Dulchavsky SA, Ruffin WJ, Johnson DA, Cogan C and Joseph CLM (2014) Use of an interactive, faith-based kiosk by congregants of four predominantly, African-American churches in a metropolitan area. Front. Public Health 2:106. doi: $10.3389 /$ fpubh.2014.00106

This article was submitted to Public Health Education and Promotion, a section of the journal Frontiers in Public Health.

Copyright (c) 2014 Dulchavsky, Ruffin, Johnson, Cogan and Joseph. This is an openaccess article distributed under the terms of the Creative Commons Attribution License (CC BY). The use, distribution or reproduction in other forums is permitted, provided the original author(s) or licensor are credited and that the original publication in this journal is cited, in accordance with accepted academic practice. No use, distribution or reproduction is permitted which does not comply with these terms. 